\title{
Editorial \\ Special Issue: The State of the Art of Thermochemical Heat Storage
}

\author{
Salvatore Vasta $(\mathbb{D}$
}

Citation: Vasta, S. Special Issue: The State of the Art of Thermochemical Heat Storage. Appl. Sci. 2021, 11, 1956.

https://doi.org/10.3390/app11041956

Received: 11 February 2021

Accepted: 19 February 2021

Published: 23 February 2021

Publisher's Note: MDPI stays neutral with regard to jurisdictional claims in published maps and institutional affiliations.

Copyright: (C) 2021 by the author. Licensee MDPI, Basel, Switzerland. This article is an open access article distributed under the terms and conditions of the Creative Commons Attribution (CC BY) license (https:// creativecommons.org/licenses/by/ $4.0 /)$.
Istituto di Tecnologie Avanzate per l'Energia "Nicola Giordano", (ITAE-CNR), Via S. Lucia Sopra Contesse n 5 , 98126 Messina, Italy; salvatore.vasta@itae.cnr.it

Nowadays, thermal energy storage (TES) is gaining a crucial role in the development of highly efficient thermal energy systems [1]. This topic is stimulating a growing interest in the scientific community, in many cases by borrowing and using, in a new and profitable way, the research results obtained in the field of heat pumps and thermally driven systems [2,3]. The proper use of TES systems can facilitate the effective exploitation of renewable energies, allowing the mismatch between energy production and demand for discontinuous energy sources and/or variable loads to be overcome. Moreover, special classes of TES systems, based on sorption or chemical reactions, can enable the long-term storage of renewable heat. The thermochemical technology is based on a reversible reaction occurring between two components, and it is associated with higher amounts of energy stored with respect to systems based on sensible heat [4]. Furthermore, it can effectively support the operation and integration of renewables in local smart grids. To prove this interesting feature, in [5] the authors reviewed the state of the art of theoretical, experimental and numerical studies available in the literature on thermochemical thermal energy storage systems and their use in power-to-heat applications, with a focus on applications with renewable energy sources to serve energy grids. The authors highlighted the advantages of the technology: flexibility, load management, power quality, continuous power supply and enhanced use of variable renewable energy sources. Such features are considered crucial elements to increase the commercial profitability of these storage systems. Eventually the authors introduced specific challenges, i.e., life span and stability of storage material, and high cost of power-to-heat/thermochemical systems, as aspects to increase the technology readiness level.

Thermochemical TES systems, especially those based on sorption processes, can allow the design and implementation of unprecedented solutions for mobile applications. In [6] we demonstrated, through an experimental activity, the feasibility of a compact system for cold storage for mobile commercial applications. In our work, we described the realization and testing of two different types of cold storage based on two innovative adsorbent reactors: a pelletized adsorber filled with commercial FAM Z02 zeolite, and a composite adsorber based on an aluminum porous structure and a SAPO-34 coating. The application of the specific testing procedure allowed the characterization of the prototypes under cold storage mode for mobile refrigeration purposes. Results showed that the prototypes can store up to $580 \mathrm{Wh}$, with an average power during the discharging phase that ranges from 200 to $820 \mathrm{~W}$ and an energy efficiency of 0.3 , thus revealing promising opportunities for future further developments.

However, such future developments must be supported by proper research carried out at material and system levels. For instance, solving issues related to adsorbent material or the investigation of new classes of zeolites can support research on more efficient, compact and lightweight sorption TES. To this aim, the authors of [7] proposed a novel silicone-SAPO34 composite material obtained through a mold foaming process activated by a dehydrogenative coupling reaction between siloxane compounds, for application in adsorption TES systems. A series of analyses and measurements of the mechanical proper- 
ties demonstrated quite a homogeneous open-cell structure and good structural stability of the foam. Moreover, the authors demonstrated that the presence of the polymeric fraction does not affect the adsorption capacity of the composite adsorbent. Finally, the authors compared the properties of the foam with those of other adsorbent materials, confirming its possible use in thermal energy storage systems.

Research at the system level provides useful information about achievable performance by integrating adsorption TES in real contexts, such as buildings and solar systems for domestic or residential purposes.

The authors of [8] investigated the theoretical limits of sorption TES, first facing the classification of thermochemical heat storages, then studying their thermodynamics. They observed that the reaction enthalpy value only varies slightly for one mole of water, thus deriving the following conclusions on the energy efficiency of closed and open TES: (i) the energy required for evaporation of water is, at least, $65 \%$ of the available energy of the reaction; (ii) the maximum theoretical energy efficiency of the system is about 1.8 . Based on those results, they calculated that a perfect thermochemical heat storage system would store up to 12 times more energy compared with conventional water storage with a temperature difference of $50{ }^{\circ} \mathrm{C}$, thus confirming that this solution is definitely competitive.

In [9], the authors presented a numerical study on the performance of a solar domestic sorption TES module operating in seven different world locations. The authors optimized the TES configuration for the Portuguese climate and then calculated its performance by varying latitude, operating conditions and solar collector tilt angle. They proved the effectiveness of the system by implementing a dynamical model and numerical simulations and by using the reduction in the annual energy consumption of a backup heater as a benchmark. The results showed that the best performances were obtained in locations where winter and summer are clearly defined, especially locations where winters are colder, and with the inclination angles of solar collectors being larger than the local latitude, except for locations with low latitudes, where the inclination angles of solar collectors are not so relevant to the system performance.

Finally, in [10] the authors proposed a novel adsorption TES system based on water and zeolite 13X for industrial applications. Their unconventional scheme was conceived so that steam production and condensation, during adsorption and desorption processes, occur in the same vacuum reactor, where the zeolite is heated and cooled. They also attempted to preliminarily assess the energy performance using numerical simulations and experiments. To this aim, they constructed a reduced-scale prototype: the limited experimental campaign produced data for the validation of the simplified model of the adsorption/desorption processes. However, the experimental campaign and the simulative activities carried out by the authors highlighted some critical issues of their system, thus indicating a lack of a suitable preliminary experimental activity, and a deep comprehension of the phenomena involved.

Funding: This research received no external funding.

Institutional Review Board Statement: Not applicable.

Informed Consent Statement: Not applicable.

Conflicts of Interest: The authors declare no conflict of interest.

\section{References}

1. Borri, E.; Zsembinszki, G.; Cabeza, L.F. Recent developments of thermal energy storage applications in the built environment: A bibliometric analysis and systematic review. Appl. Therm. Eng. 2021, 116666. [CrossRef]

2. Freni, A.; Maggio, G.; Vasta, S.; Santori, G.; Polonara, F.; Restuccia, G. Optimization of a solar-powered adsorptive ice-maker by a mathematical method. Sol. Energy 2008. [CrossRef]

3. Palomba, V.; Dawoud, B.; Sapienza, A.; Vasta, S.; Frazzica, A. On the impact of different management strategies on the performance of a two-bed activated carbon/ethanol refrigerator: An experimental study. Energy Convers. Manag. 2017, 142, 322-333. [CrossRef]

4. Zhang, Z.; Wang, J.; Feng, X.; Chang, L.; Chen, Y.; Wang, X. The solutions to electric vehicle air conditioning systems: A review. Renew. Sustain. Energy Rev. 2018, 91, 443-463. [CrossRef] 
5. Airò Farulla, G.; Cellura, M.; Guarino, F.; Ferraro, M. A Review of Thermochemical Energy Storage Systems for Power Grid Support. Appl. Sci. 2020, 10, 3142. [CrossRef]

6. Vasta, S.; Palomba, V.; La Rosa, D.; Bonanno, A. Adsorption Cold Storage for Mobile Applications. Appl. Sci. 2020, 10, 2044. [CrossRef]

7. Calabrese, L.; De Antonellis, S.; Vasta, S.; Brancato, V.; Freni, A. Modified Silicone-SAPO34 Composite Materials for Adsorption Thermal Energy Storage Systems. Appl. Sci. 2020, 10, 8715. [CrossRef]

8. Kuznik, F.; Johannes, K. Thermodynamic Efficiency of Water Vapor/Solid Chemical Sorption Heat Storage for Buildings: Theoretical Limits and Integration Considerations. Appl. Sci. 2020, 10, 489. [CrossRef]

9. Fernandes, M.S.; Costa, V.A.F.; Brites, G.J.V.N.; Gaspar, A.R.; Costa, J.J. Performance Analysis of a Solar DHW System with Adsorption Module Operating in Different World Locations. Appl. Sci. 2019, 9, 5480. [CrossRef]

10. di Palo, M.; Sabatelli, V.; Buzzi, F.; Gabbrielli, R. Experimental and Numerical Assessment of a Novel All-In-One Adsorption Thermal Storage with Zeolite for Thermal Solar Applications. Appl. Sci. 2020, 10, 8517. [CrossRef] 